\title{
Creativity and Critique as Formative Processes in Design Thinking
}

\section{Brad Hokanson $^{1} \cdot$ Robert Kenny ${ }^{2}$}

Published online: 19 June 2020

(C) Association for Educational Communications \& Technology 2020

\section{Introduction}

Creativity is highly affected and primarily improved through formative processes. Those processes center on assessment during the learning effort and can effectively support the development learners' intellectual skills. This issue of $J D F L$ primarily focuses on design education and the design process and are examined as models for application in other fields. As such, the various aspects of design thinking are explored with their relationship to developing creativity. Particular attention is paid to using many of the representative short studies included in this issue, which present examples of formative models and critiques for learning and instruction.

We have selected the concept of "critique" on purpose. As often used in the design and creative fields, "critique" is a conversational, formative method of interaction and assessment, and is offered as one that can also be used by instructional designers.

\section{Design as a Way of Thinking About Things}

The core aspect of design is a way of thinking and knowing, i.e., it is an epistemology that builds from the process of design as a way of learning and investigation. This process consists of a variety of methods, processes, knowledge application, and skills which are commonly shared across design fields (Nelson \& Stolterman, 2001/Nelson and Stolterman 2012; Cross 2001; Henriksen et al. 2017).

Often packaged as "Design Thinking," these procedural methods also have been distilled, codified, and exported

Brad Hokanson

brad@umn.edu

1 University of Minnesota School of Design, University of Minnesota, Minneapolis, MN 55108, USA

2 College of Education, Florida Gulf Coast University, Fort Myers, FL 33965, USA widely to other domains including business and education (Martin and Martin 2009; Plattner et al. 2015; Kelley and Kelley 2013). While a simplified, codified application of design thinking has been translated to external, non-design use, the results have been mixed at best (Kolko 2018; Vinsel 2018). As Bruce Nussbaum noted, design thinking is "a whole new process that promised to deliver creativity" to the world of big business and focused on process efficiency. But "from the beginning, the process of Design Thinking was a scaffolding for the real deliverable: creativity" (Nussbaum, unpaged, 2011).

\section{Design Learning}

The design process offers a structure, opportunities to develop creative talents, as well as a range of other complex skills. These opportunities also exist for problem-based learning and other learning activities that parallel the design process. Most design education begins with the consideration of multiple ideas to initiate projects. It is common for an instructor in an architecture or graphics class to require three design ideas to be presented or 20 thumbnails to examine different forms of layout.

Design as an academic endeavor is not limited solely to solving problems. Lawson and Dorst (2009) describe the design process (and design thinking) as having a number of procedural steps that provide opportunities to encourage creativity. These early phases of "formulating" include identifying and finding problems. The idea of framing (or re-framing) a problem that is posed offers opportunities for early exploration and creativity.

Framing is a "re-directioning" or the re-naming of an initial problem description, which can lead to substantially different outcomes. "Whether we think of it as the reformulation of problems or the identification of elements, making them explicit and developing their characteristics is not clear-cut but is a substantial part of the design project. This is clearly an 'important and central design skill'” (Lawson and Dorst, 2013, 
p.50). By its nature, reframing encourages diverse output. As a long-term habit, this recognition and use of semantic reshaping can be considered a form of critical thinking and the weighing initial viewpoints.

Another aspect of the design process is a series of interpretive and developmental moves. An initial "move," also referred to as a gambit, leads to a subsequent set of decisions. Different beginnings lead to different directions, each reflecting different conceptual orientations and attitudes. These moves interpret the design challenge, the context, and the constraints of a given problem. They also build on the framing of the initial challenge. Subsequently, other developmental moves occur logically and as a consequence of earlier decisions. Inherent in the design process is an ongoing search and evaluation of a variety of answers. This can be described as posing and evaluating multiple hypotheses and subhypotheses and is relevant to many other fields of inquiry.

Design learning generally occurs through a process of critique, a review of smaller studies and result in a conversation or narrative that focuses on the results of these initial designs. These shortened works are treasured for their creativity in which failure is actually valued. As Brown once said in his book Change by Design: "fail often so we may succeed more quickly" (2009). In other words, entrepreneurial thinking is not about developing infallible technical expertise or the ability to develop declarative knowledge - it is the skill of developing original and well-structured ideas.

This illustrates a significant difference in design education; there is a focus on the formative elements of learning as necessitated by the design process, and not as much on the summative aspects or results of the process. Creativity (and therefore knowledge about a topic or a solution to a problem) develops through that formative process.

\section{Creativity}

As noted previously, an important aspect of the design process and design thinking is creativity. Designers need to have the ability to solve unique and complex challenges via creative thinking. This describes a skill, creativity, and it can be applied throughout the fields of design, and at all levels of practice. This is one that is generally described as a twenty-firstcentury skill. Popularly, creativity is not well defined, but researchers in the discipline have a base definition that is widely used and accepted (Mumford 2003; Plucker et al. 2004; Bronson and Merryman 2010; Sternberg 2011).

Creativity can be defined as the capability to develop ideas that are both original and valuable (Robinson 2011). While the paired terms vary semantically, the practice of design can be seen to parallel this standard definition of creativity, and from that definition broader definitions emerge: "A basic, oftencited definition of creativity describes it as the process of creating ideas, artifacts, processes, and solutions, that are novel and effective... Design involves directing creativity towards goals, actions, and purpose around real-world issues" (Henriksen et al. 2017, p. 4). Torrance describes creativity, and illustrates the shared qualities of design and creativity:

"[Creativity is] a process of becoming sensitive to problems, deficiencies, gaps in knowledge, missing elements, disharmonies, and so on; identifying the difficulty; searching for solutions, making guesses, or formulating hypotheses about the deficiencies: testing and retesting these hypotheses and possibly modifying and retesting them; and finally communicating the result (Torrance 1972, p. 5).

This is manifest and applied in design through divergent and convergent thinking, the two principal aspects of creativity. Divergent thinking is the search for different and new forms and ideas. The second, convergent thinking, focuses on one answer and its improvement. Most education focuses on the convergent aspects, seeking a single correct answer. Design processes and design education provide a range of opportunities for divergent thinking, the generative aspects of the process, while in its development of domain knowledge, the development of convergent skills is honed.

\section{Toward the Development of Creativity}

Ironically, designers are viewed by the general public as being highly creative. While design may be misunderstood as a field, this may also be due to the theoretical familiarity to the arts or to experience with novel ideas developed by designers. This is not, however, because of specific evidence of creativity per se. Designers may be considered creative because they possess skills that are distinguishing, but not because they are measurably more creative than the general population with comparable education levels. Education in design focuses on the development of domain expertise and not specifically on enhancing creative skills. Creativity development is often not addressed specifically, as with other educational fields.

Development of creativity in design and elsewhere requires an evolution of teaching and subsequently of learners. An important shortfall of design education is a failure to implicitly develop creativity in learners and new design — both as a curricular direction and as a qualitative evaluation. Developing creativity in new designers is a long-term effort and critical to the field. The design process itself, with its iterative subjective judgments and assessments, offers a wide range of opportunities for the development of learner creativity. Each there is a subjective judgment, there is an opportunity for divergent 
thinking. Needed, however, is a change of orientation of instructors in increasing this needed skill.

This requires a change of focus on the educational process; on the formative aspects, and not the summative aspects of learning. Creativity happens along the way.

The concepts of reframing ideas, making incremental interpretive moves, creativity, and divergent and convergent thinking are central to design thinking, which we suggest is at the heart of formative design. That is why readers of this journal will note an abundance of reporting on smaller research activities and case studies in the various articles. They are also integral to the central theme of last year's Writers' Workshop sponsored by the Journal and the three universities that took place at last year's AECT Annual Convention. The articles included in this issue are representative of the work submitted and conversations that took place among the participants.

\section{References}

Bronson, P. \& Merryman, A. (2010). The creativity crisis. Newsweek. Retrieved from http://www.newsweek.com/2010/07/10/thecreativity-crisis.print.html

Cross, N. (2001). Designerly ways of knowing: Design discipline versus design science. Design Issues, 17(3), 49-55.

Henriksen, D., Richardson, C., \& Mehta, R. (2017). Design thinking: A creative approach to educational problems of practice. Thinking Skills and Creativity, 26, 140-153.
Kelley, T., \& Kelley, D. (2013). Creative confidence: Unleashing the creative potential within us all. Toronto: Crown Business.

Kolko, J. (2018). "The divisiveness of design thinking." ACM interactions, May-June, 2018: Retrieved from http://interactions.acm.org/ archive/view/may-june-2018/the-divisiveness-of-design-thinking

Lawson, B., \& Dorst, K. (2009). Design expertise. Amsterdam: Elsevier.

Martin, R., \& Martin, R. L. (2009). The design of business: Why design thinking is the next competitive advantage. Harvard Business Press.

Mumford, M. D. (2003). Where have we been, where are we going? Taking stock in creativity research. Creativity Research Journal, $15,107-120$.

Nelson, H. G., \& Stolterman, E. (2012). The design way: intentional change in an unpredictable world - foundations and fundamentals of design competence. Cambridge: MIT Press.

Nussbaum, B. (2011). Design thinking is a failed experiment. So what's next. Fast company.

Plattner, H., Meinel, C., \& Leifer, L. (Eds.). (2015). Design thinking research: Making design thinking foundational. Springer.

Plucker, J., Beghetto, R. A., \& Dow, G. T. (2004). Why Isn't creativity more important to educational psychologists? Potentials, pitfalls, and future directions in creativity research. Educational Psychologist, 39(2), 83-96.

Robinson, K. (2011). Out of our minds. Tantor Media, Incorporated.

Sternberg, R. J. (2011). "Creativity". Cognitive psychology (6th ed.). Cengage Learning. p. 479.

Torrance, P. (1972) Verbal tests. Forms A and B - figural tests, forms A and B. The Torrance tests of creative thinking - norms - technical manual Research Edition. Princeton, New Jersey: Personnel Press. p. 6.

Vinsel, L (2018). "Design Thinking Is a Boondoggle". The Chronicle of Higher Education. 2018-05-21. Retrieved 6.10.2019.

Publisher's Note Springer Nature remains neutral with regard to jurisdictional claims in published maps and institutional affiliations. 